STUDIA ROSSICA POSNANIENSIA, vol. XLI: 2016, pp. 487-499. ISSN 0081-6884.

Adam Mickiewicz University Press, Poznań

\title{
ПРАГМАТИЧЕСКИЕ И ДИДАКТИЧЕСКИЕ УСЛОВИЯ ПОНИМАНИЯ ИНОЯЗЫЧНОГО ТЕКСТА
}

\author{
PRAGMALINGUISTIC AND DIDACTIC CONDITIONS \\ OF UNDERSTANDING A FOREIGN LANGUAGE TEXT
}

\author{
WŁADYSŁAW WOŹNIEWICZ
}

\begin{abstract}
The article describes the linguistic, cultural, pragmatic conditions necessary for understanding foreign language texts. The main postulate of the article is that an adequate understanding of a text is dependent both on knowing the meaning of the individual words and interpreting their meaning in the text as a whole. A substantial and crucial part of the article is dedicated to the description of didactic activities for teachers aiming to develop the skills required for understanding foreign texts, both for beginners and advanced learners.
\end{abstract}

Władysław Woźniewicz, Uniwersytet im. Adama Mickiewicza w Poznaniu, Poznań - Polska,wozniew@amu.edu.pl

На тему иноязычного текста как средства овладения иностранным языком имеется, как известно, богатая литература. Во всех работах (научных монографиях, статьях, методических пособиях), посвященных восприятию текста, центральным концептом является понимание текста. Однако психолингвистический аспект понимания текста и формирование умения понимать текст в процессе обучения иностранному языку толкуется отдельными авторами по-разному. Некоторые из них утверждают, что условием и показателем понимания является знание значений единиц текста - слов, словосочетаний и умение излагать содержание текста ${ }^{1}$. Подобное, редуцированное, объяснение концепта понимание отражается в методике формирования умения понимать текст, так как не учитываются психические, культурно-когнитивные, соционормативные и эмоциональные аспекты восприятия и воздействия смыслового содержания текста на читателя.

В настоящее время большинство авторов признает концепцию, согласно которой понимание иноязычного текста не сводится к знанию

\footnotetext{
${ }^{1}$ См., например: A. P a 1 i ń s k i, Sprawność czytania w nauczaniu języka rosyjskiego, Warszawa 1983; H. K o m o r o w s k a, Metodyka nauczania języków obcych, Warszawa 2001.
} 
значений слов, составляющих текст. Необходимо также уяснить смыслы слов и других единиц текста и их образные представления. Существенны также и другие факторы, обусловливающие понимание, такие, например, как степень усвоения языка, личный когнитивный капитал реципиента, вид текста и др.

Приведенные вводные замечания имплицируют предмет, проблематику и цель настоящей статьи. Итак, предметом рассуждений будут прагмалингвистические, личностные и лингводидактические условия понимания текста. Обсуждаемая проблематика в рамках этого предмета учитывает:

1) уяснение концептов значение, смысл, образное представление как основных категорий коммуникативных интеракций в триаде автор - текст - реципиент / читатель, проявляющихся в процессе апперцепции содержания текста;

2) прагмалингвистические, личностные и дидактические условия понимания текста на начальном / базовом и продвинутом этапах овладения иностранным языком;

3) представление типичных причин, затрудняющих адекватное понимание читаемых текстов.

Основная цель состоит в раскрытии возможности оптимизировать формирование умения понимать иноязычные тексты.

Переходя непосредственно к намеченной проблематике, приведу в сжатом виде определения названных выше концептов восприятия текста.

Концепт значение в литературе предмета представлен, как известно, в различных версиях. Ю.Н. Караулов пишет прямо о „разбухании” значений ${ }^{2}$, представленных в лингвистике: семантическое, лексическое, понятийное, добавим еще - денотативное, первичное, обыденное, универсальное, смысловое и др. Из различных авторских версий определения значения можно выделить следующие константные дескрипторы: кодифицированность, конвенциональность, информация, знание, инвариантность содержания ${ }^{3}$.

Гораздо сложнее представляется понимание концепта смысл, нередко индентифицируемого с содержанием значения. Между тем, как утверждают Ch. Baylon и X. Mignot, смысл в отличие от значения физически не передается. Смысл существует лишь для ума и в уме, и в нем

2 Ю.Н. К а р а у л о в, Русский язык и языковая личность, Москва 1987, с. 210.

3 Подробнее см., напр.: И.А. 3 и м н я я, Психология обучения неродному языку, Москва 1989, с. 10; И.М. К о б о з е в а, Две ипостаси содержания речи: „значение” u „смысл”, [в:] Язык о языке, ред. Н.О. Арутюнова, Москва 2000, с. 323; А.А. Л е о н т ь е в, Психология общения, Москва 2007, с. 139. 
остается ${ }^{4}$ Трудно полностью согласиться с этим утверждением, ведь все, что появляется в уме, в том числе смысл, эмоции, потенциально может изъявляться, передаваться физически, вербально с учетом необходимой амплификации. Например, смысл значения приличие, неприиично может излагаться, передаваться в зависимости от обстановки в разных фразах со словами обманывать, врать, обижать, бесстыдный, жадный и т. п. и их синонимическими определениями.

Во избежание неоднозначности уточним, что пониманию концепта обычно приписываются такие константные дескрипторы, как субъективность информации / содержания, интерпретивная выводность содержания, ситуативно-коннотативная обусловленность, видоизменяемость, культурно-идеологическая маркированность и др. ${ }^{5}$ Иными словами, можно полагать, что смысл слова, словосочетания, фразы - это субъективный, индивидуальный результат сиюминутной или окказиональной интерпретации, своеобразная „добавочная стоимость", привнесенная к содержанию значения языковой единицы текста.

Осознание значения и смысла языковых единиц иноязычного текста является необходимым условием его понимания. Однако, как уже было сказано, понимание значения слов не всегда равнозначно пониманию содержания фразы, высказывания с этими словами, так как понимание - это сложный когнитивно-мыслительный процесс, обусловленный рядом личностных факторов реципиента. Как утверждает В. 3. Демьянков, этот процесс понимания, направленного на установление смысла некоторого объекта - слова, текста, является результатом когнитивной (речевой) деятельности, т. е. интерпретации воспринимаемого объекта. Интерпретацию, нацеленную на определение смысла данного объекта, обусловливают такие факторы, как:

- использование языкового знания,

- опыт в переосмыслении ранее сказанного / прочитанного,

- реконструкция интенции автора,

- имеющиеся презумпции интерпретатора / реципиента и другие, в частности межличностные, факторы.

„Интерпретационные операции - когнитивные процедуры - выглядят как построение и верификация гипотез-предвосхищений"6, - резюмирует автор.

${ }^{4}$ Ch. B a y 1 o n, X. M i g n o t, Komunikacja, Kraków 2008, c. 26.

5 Об указанных признаках концепта смысл см.: Д.Б. Г у д к о в, Теория и практика межкультурной коммуникации, Москва 2003, с. 244; И.М. К о б о з е в а, указ. соч., с. 320; А.Р. Л у р и я, Язык и сознание, Москва 1979, с. 53.

${ }^{6}$ В.3. Д е м ь я н к о в, Понимание, [в:] Краткий словарь когнитивных терминов, ред. Е.С. Кубрякова и др., Москва 1996, с. 124-126. 
Стало быть, интерпретация определяется такими факторами, как языковой образ мира личности интерпретатора, его знания и установка, проявлением которых является, среди прочего, эмпатия. Понятие эмпатия здесь будет пониматься как сопереживание согласия, апробации представленных в тексте образов мира жизни или их дезапробации, иными словами, как ощущение эмоциональной, эстетической удовлетворенности или дискомфорта, диссонанса и т. п. соответственно иллокутивной силе воспринимаемого текста.

В учебных условиях формирование умения понимать высказывания, тексты на уровне узнавания значений языковых единиц - это исходная необходимая задача. Формирование умения распознавать / уяснять частные смыслы значений языковых единиц - это задача в равной степени обязательная, так как их осмысление является условием адекватного понимания, особенно понимания художественного текста. Поэтому чтение повествовательных, в том числе художественных текстов, в учебной практике не должно ограничиваться извлечением фактуальной информации о событиях, действиях, поведении, состояниях персонажа, о реалиях и артефактах иноэтнического мира.

Чтение текста, особенно художественного, имеет, как известно, синергетический характер. Взаимодействие текста и реципиента проявляется в возбуждении не только в познавательной сфере, но и эмоциональной, эстетической и особенно образной сферах. Как утверждает А.А. Залевская7, значение, смысл слова актуализируются в психике в составе некоторого образа при взаимодействии знания и переживания отношения к этому знанию. Согласно этому тезису, значения, смыслы некоторых языковых единиц воздействующего текста предстают в актах его перцепции в виде создаваемых/воссоздаваемых образных представлений. У читателя актуализируются или воссоздаются образные представления / репрезентации, соотносимые с их словесными обозначениями. Достаточно сравнить, например, первые строки стихотворения М.Ю. Лермонтова:
Когда весной разбитый лед
Рекой взволнованной идет,
Когда среди полей местами
Чернеет голая земля,
И мгла ложится облаками...

и потенциально воссоздаваемые образные представления весны в словосочетаниях этого стихотворения.

7 А.А. 3 а л е в с к а я, Некоторые проблемы теории понимания текста, „Вопросы языкознания" 2002, № 3, с. 62-74. 
Подытоживая приведенные теоретические положения, можно сказать, что понимание текста - это последовательность констатации /осознания значения, уяснения смысла и субъективного воссоздания образного представления языковых единиц текста и, в конечном счете, смысла / идеи самого текста. Добавим, что эта последовательность - это теоретический конструкт, результат научного исследования. В действительности компоненты этой последовательности, как утверждает А.А. Залевская, „в реальных жизненных процессах (в норме) функционируют в едином ансамбле". Они актуализируются в уме только

в ситуациях затруднений в общении или при чтении текста, когда обнаруживаются смысловые или нормативно-языковые „нестыковки”, заставляющие носителя языка задуматься, вынести на „табло сознания” различные варианты понимания и принять решение о выборе их возможных альтернатив 8

Конечно, в учебных условиях правильный выбор этих альтернатив зависит от удачного содействия преподавателя.

Переходя непосредственно к проблематике лингводидактических условий формирования умения понимать иноязычный текст, сначала сжато охарактеризую особенности этого формирования на начальном, базовом уровне, а затем, более обстоятельно, - на продвинутом этапе. Напомню тривиальное в этом контексте положение о том, что первым необходимым условием чтения вообще и чтения иноязычного / русского текста является сформирование совокупности навыков, связанных с понятием техники чтения, т. е. сформирование навыков совместного, синхронного функционирования / взаимодействия основных компонентов механизма чтения. К ним, как известно, принадлежат:

1) зрительное восприятие и узнавание образов / графем - буквосочетаний, слов, словосочетаний,

2) соотнесение воспринимаемых зрительных образов графем со звуко-слуховыми и речедвигательными (артикуляционными) образами,

3) узнавание значений новых единиц текста и установление поचит, т. е. понимание новой фактуальной информации,

4) прогнозирование (антиципирование) в ходе чтения слов и их флективных форм,

5) желаемая скорость чтения: 100-120 слов в минуту благодаря поступающей редукции речедвижений в чтении про себя,

6) другие оперативные компоненты чтения с пониманием - такие как приобретение необходимого запаса слов и элементарного умения узнавания (семантизации) значений новых слов на основе контексту-

8 Там же, с. 70. 
альной догадки, соответствующая корреляция между информацией, содержащейся в тексте, и общими знаниями читателя (доступность текста) и др.

Из приведенной общей характеристики сформированности навыков и умений чтения на основном (базовом) уровне владения иностранным языком следует, что и понимание читаемых текстов ограничивается восприятием текстовой информации главным образом на уровне значений языковых единиц текста. Иначе говоря, подобное понимание состоит в извлечении, констатации фактуальной информации. На основе личного опыта и сведений, полученных от опрашиваемых преподавателей русского языка, этот уровень понимания достигается, если незнакомая лексика не превышает 10-15\% неспециализированного текста. Однако, как известно, пробелы в знаниях отдельных слов не исключают воздействия текста, особенно поэтического, на личностную, эмоциональную и эстетическую сферы со всеми дидактическими и общеобразовательными последствиями. К примеру, можно сравнить стихотворения А.С. Пушкина Буря мглою небо кроет, // Вихри снежные крутя..., Уж небо осенью блистало, // Короче становился денъ... или некоторые произведения Л.Н. Толстого из цикла Детские рассказы.

Понимание на уровне значений слов мы можем истолковать вслед за А. Вежбицкой в плане лексических универсалий, иначе - универсальных семантических примитивов, „то есть понятий, которые могут быть лексикализованы (в виде отдельных слов или морфем) во всех языках мира"9. Как утверждает А. Вежбицкая, „понятийные примитивы типа good, bad, а также want, know, say, think не являются артефактами английского языка, а принадлежат универсальному алфавиту человеческой мысли. Они действительно имеют семантические эквиваленты во всех или почти во всех языках мира"10. Например, понимание предложений типа Сегодня мы увидим всех наших друзей или Думаю, что он знает хорошо, что ты не хочешь пить вина не представляет затруднений, если, конечно, усвоены/ известны означения (звуко-слуховые, зрительные) значений слов в русском, немецком, английском и прочих европейских языках. Но в ином контексте понимание этих же слов, например весь, видеть, может быть затруднительным, если они отмечены добавочным смысловым значением, ср., напр.: Сын весь В отияа или Видищъ ^и, какой он добрый.

Стало быть, понимание на уровне исходных, первоначальных значений слов в процессе чтения на начальном этапе усвоения языка ограничивается распознаванием этих слов и их идентифицированием

${ }^{9}$ А. В е ж б и ц к а я, Язык. Культура. Познание, Москва 1996, с. 330.

10 Там же, с. 334. 
согласно конвенционально приписанным им общепринятым значениям. При этом в лингводидактическом аспекте существенно, чтобы эти слова в большей части принадлежали к кругу лексических универсалий либо их производных во избежание и/или для ограничения неправильного их осмысливания. Конечно, это не снимает известных усилий, связанных с усвоением навыков, слагающихся на технику чтения и на запоминание самих значений этих слов.

Формирование умения понимать текст на начальном этапе не представляет особых методических затруднений. Применяемые процедуры и различные формы учебных заданий общеизвестны. Источником возможных затруднений могут быть такие факторы, как, например, несоответствующий педагогический стиль управления учением языку, несоблюдение известных принципов педагогической коммуникации/общения, особенно эмпатии, ассертивности, надлежащей иллокутивной экспрессии и т. п.

Гораздо сложнее представляется формирование умения понимать текст на продвинутом этапе, после усвоения основ языка. На этом этапе необходимо увеличивать объем синхронного распознавания и осмысления значений слов, фраз, употребляемых в различных вариантах непрямого значения, часто в метафорическом, аллегорическом смысле. Подобные полисемантические слова, выражения, наделенные разным семантическим составом, а также слова, означающие различные, в том числе исторические факты, события, реалии иноэтнического мира, значительно затрудняют понимание содержания текста. Их уразумение и осмысление зависит от личного живого знания реципиента, его возможных презумпций и качества пресуппозиций. Как утверждает А.А. Залевская, такое

живое знание [...] обеспечивает понимание текста через встречное конструирование ситуации на основе знания о том, что, как, когда, зачем и почему, с какими целями, результатами и следствиями было, бывает, может или не может случиться в реальном или воображаемом мире ${ }^{11}$

Парафразируя известное изречение Л. Виттгенштейна Границы моего мира суть границы моего языка, мы можем сказать, что границы (глубина) понимания текста лимитированы границами (глубиной) знания реципиента и его знания языка. Столько его понимания текста, сколько его знания об осмысленных значениях слов и их образных представлениях, относящихся к данному этно-социокультурному миру. Ниже приводится попытка пояснить это положение на примере прочтения стихотворения М.Ю. Лермонтова Парус (1832).

11 А.А. 3 а л е в с к а я, указ. соч., с. 65. 


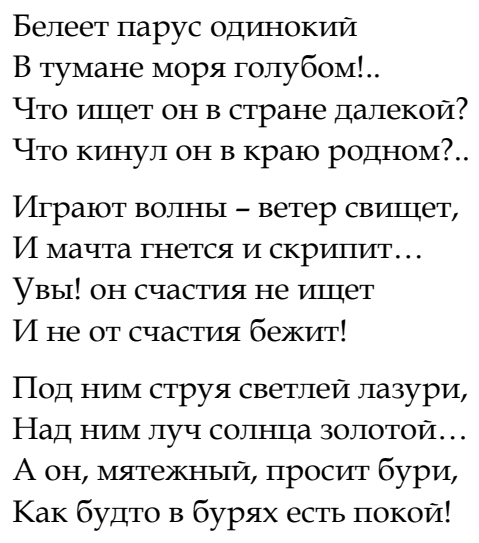

Образно-языковые представления в строках этого стихотворения с позиции неискушенного ученика-лицеиста или студента-русиста могут восприниматься и пониматься или на уровне прямых значений образующих их слов, или на уровне осмысления этих же значений. В первом случае, довольно распространенном в учебной практике, теряется смысл отдельных строк и главный смысл / идея целого стихотворения. Во втором случае понимание на уровне уразумения и постижения смысла этих же строк и целого стихотворения довольно затруднительно, так как требуется у реципиента не только минимального знания об историческом времени жизни автора произведения, но и некоторого воображения и умственно-эмоционального вовлечения. Поэтому со стороны преподавателя необходимы удачные фацилитативные действия. При этом надлежит, во-первых, учесть, что понимание смысла художественного произведения может изменяться в данном историческом времени соответственно культурно-ценностным, идеологическим условиям жизни в данной эпохе, во-вторых, оно - это понимание - бывает часто субъективным в зависимости от характера личности и интерпретации реципиента.

Ниже предлагается „субъективный” авторский план сценария учебных действий преподавателя, нацеленных на уразумение смысла образно-языковых представлений, содержащихся в отдельных строках, и смысла/ идеи целого стихотворения Парус.

1. Сообщение учащимся темы, задач занятия и семантизация ключевых слов.

2. Сжатое изложение в форме беседы сведений об эпохе и авторе стихотворения, его судьбе как одинокой бунтующей личности.

3. Осознание учащимися понятий олищетворение, аллегория, аллегорический, аллегорическое стихотворение, картина, скульптура.

4. Декламация преподавателем стихотворения Парус. 
5. Самостоятельное, про себя, чтение стихотворения учащимися с задачей осмысления очередных строк.

6. Действия преподавателя, в том числе некоторые действия, связанные с методом coaching,a (напр. вопросы, призывы, активизация личного знания и опыта, перевод употребленных учащимися польских слов, подсказки, в том числе подсказки недостающих слов и др.), направленные на осознание и высказывание смыслового содержания понятий одинокий, одиночество в возможных ситуативных представлениях.

7. Осознание и вербализация учащимися образных представлений одиночества, одинокого человека - его состояний, переживаний, поведения, зафиксированных в отдельных строках стихотворения Парус.

8. Опыт художественного чтения стихотворения двумя-тремя учащимися.

9. Переход от анализа стихотворения Парус к развитию русской речи, например на тему Одиночество молодых людей $b$ современном мире, или Одиночество польских „европейских сирот”, или же на предложенную самими учащимися тему. Примеры употребления / усвоения ключевых слов и выражений:

переживание, чувство, тоска, покинутость, дружеские связи, низкая самооценка, боязливость, стыдливость, скрытый / неоткровенный, агрессия / агрессивность, бунт / бунтоваться, никто меня не понимает / не любит, „один в толпе”, „один средь шумного бала”, „скучно и грустно, и некому руку подать", „Долой такой порядок!” и т. п.

Разумеется, что отбор ключевых слов и сам учебный дискурс будет зависеть от учебного времени, от уровня владения иностранным языком и от откровенности в межличностных отношениях в языковой группе, а также от удачного стимулирования речевой активности преподавателем.

Из приведенных рассуждений следует, что осмысленное понимание иноязычного, инокультурного текста, особенно поэтического, лирического произведения, зависит от ряда субъективных факторов реципиента. Оно, это понимание, нередко затруднительно и для среднеобразованных монокультурных реципиентов, а для инокультурных реципиентов, как утверждают некоторые исследователи, полное осмысленное понимание иноязычного художественного текста непостижимо $^{12}$. Оно возможно на уровне значений слов, составляющих текст, а на

12 Как справедливо замечает Д.Б. Гудков,

нужно добиваться не того, чтобы иностранец начал воспринимать тот или иной текст как русский, так как это невозможно, но того, чтобы инофон понял, какое представление имеет об этом тексте русский и чем это представление мотивировано [...].

(Д.Б. Г у д к о в, указ. соч., с. 258). 
уровне осмысленных образно-языковых представлений лишь приблизительно при условии надлежащего методического управления.

Это методическое управление, т.е. соответствующие фацилитативные действия преподавателя, может стать результативным, если он обладает минимумом знаний о типичных барьерах, являющихся причиной затруднений и неудач правильного восприятия и понимания текста. На тему барьеров, затрудняющих адекватное понимание текста имеется богатая литература ${ }^{13}$. На основании избранных работ ${ }^{14}$ ниже указаны - по необходимости в сокращенном виде - наиболее типичные факторы, затрудняющие понимание инофоном иноязычного текста.

1. Языковые барьеры / причины непонимания. У отдельных реципиентов они могут быть различные. Наиболее типичными являются следующие:

1) ограниченный запас слов;

2) знание слов только на уровне первичных значений;

3) различия в „этнических картинах мира”, отражающие специфику распределения значений элементов окружающей действительности и впоследствии специфику их восприятия. Например, понятие снегоnад в русском языке, в отличие от польского языка или тем более от английского, представлено богатым составом словесных означений: пурга, метель, буран, снежная буря, вьюга, поземка и т. п. Подобным образом представляются переживания некоторых эмоций, например печаль, тоска, грусть, уныние, скука, или положительные / отрицательные оценки степени качества;

4) неосмысление слов, словосочетаний, фраз метафорического характера, в том числе лексико-фразеологической сочетаемости, напр.: быть на хорошем счету, жить одним домом, дать ему дорогу, положить на себя руки и т. п.

13 См., напр.: С.Г. Т е р - М и н а с о в а, Язык и межкультурная коммуникация, Москва 2000; M. G о 1 k a, Bariery w komunikowaniu i społeczeństwo (dez)informacyjne, Warszawa 2008.

${ }_{14}$ См., напр.: Е.М. В е р е щ а г и н, В.Г. К о с т о м а р о в, Язык и культура. Лингвострановедение в преподавании русского языка как иностранного, Москва 1976; Д.Б. Г у д к о в, указ. соч.; В.В. К р а с н ы х, „Свой” среди „чужих": миф или реальность?, Москва 2003; Н.В. К у л и б и н а, О когнитивном и коммуникативном аспектах чтения художественной литературы, [в:] Материалы ІХ Конгресса МАПРЯЛ, Братислава-Москва 1999, с. 274-289; Ю.А. С о р о к и н, Взаимодействие рециииента и текста: теория и прагматика, Москва 1978; W. W о ź $\mathrm{n}$ i e w i c z, Текстовые и внетекстовые лингвокогнитивные лакуны в прочтении художественного текста $b$ инокультурных условиях как иингводидактическая проблема, [в:] Glottodydaktyka i jej konteksty interkulturowe, red. A. Wołodźko-Butkiewicz, W. Zmarzer, Warszawa 2006, с. 31-38 и др. 
5) Языковые выражения, являющиеся персонификацией / олицетворением каких-либо реалий, артефактов, а также слова, фразы, сочетающие параллельно экспрессивную функцию (означение эмоциональных состояний) и поэтическую функцию (необычная форма означения смыслового содержания). Достаточно сравнить, например, фразы из стихотворений М.Ю. Лермонтова: Мачта гнется и скрипит; Один я здесь, как изарь воздушный; И тягостно мне счастье стало, // Как для изаря венеи.

2. Когнитивные барьеры / причины, связанные с незнанием исторических и современных реалий, артефактов действительности, означенных словами, выражениями, имеющимися в текстах, в том числе в текстах художественной литературы. Для реципиента они являются пробелами, затрудняющими понимание текста. В научной литературе (см., например, указанные выше работы Ю.Н. Караулова, Д.Б. Гудкова, А.А. Залевской) эти пробелы соотносятся с недостатками в знаниях, связанных с понятиями пресуппозиция 15 , прецедентные феномены 16 . Ниже приводятся примеры потенциальных когнитивных пробелов у иноэтнического реципиента в избранных видовых сферах знания:

1) культурно отмеченные нормы межличностных отношений, этикетные поведения, ритуалы, например в ситуациях празднования каких-либо событий, памятных дней;

2) свойственные русскому миру реалии быта, напр.: солянка, блин, пельменная, русская баня, путевка (b жизнъ), красный уголок и т. п.;

3) прецедентные тексты, фразы, прецедентные высказывания, например фразы из романа Евгений Онегин: Но я другому отдана, // Я буду век ему верна или В Москву, на ярмарку невест!, а также различные высказывания, фразы типа Не будь казанской сиротой, Погиб, как швед под Полтавой, У каждого Наполеона свое Ватерлоо, И на нашей улице будет праздник, Незваный гость хуже татарина и т. п.;

4) символы и разные артефакты, например государственные, архитектурные символы, разные достопримечательности и т. п.;

5) архаизмы, историзмы, в том числе исторические прецедентные имена, выражения, напр.: Куликово поле, Смутное время, опричник, лищние люди, настоящий стахановеи, похож на Павлика Морозова и множество подобных.

15 Понятие пресуппозиция здесь понимается как совокупность знаний индивида, в том числе минимум лингвострановедческих знаний, личный опыт и умения реципиента.

16 Понятие прецедент/прецеденты вслед за Д.Б. Гудковым понимается здесь в упрощенном виде, т. е. как сложившиеся в этнической культуре, актуализирующиеся в общении высказывания (прецедентные высказывания, ситуации), а также канонизированные тексты, культурные реалии, артефакты. 
Приведенные примеры потенциальных языковых и когнитивных барьеров далеко не исчерпывают возможные затруднения в понимании высказываний, текстов иноязычным реципиентом. Эти затруднения особенно досадны в ситуациях, когда все слова высказываний, фраз ему знакомы, а смысла содержания он не понимает.

Рассматриваемые вопросы, касающиеся знаний о лингвокультурных и прагматико-дидактических условиях понимания текстов иноэтническим реципиентом, остаются все еще открытыми, так как в эпоху глобальной коммуникации и нарастания межличностных интеркультурных интеракций необходимо эти знания расширять, поскольку они могут стать мостами на пути конструктивного взаимопонимания, взаимодействия и общения. Этому должна способствовать инновационная учебная практика в школе и вузе.

\section{Библиография}

В е ж б и ц к а я А., Язык. Культура. Познание, Москва 1996.

В е р е щ а г и н Е.М., К о с т о м а р о в В.Г., Язык и культура. Лингвострановедение В преподавании русского языка как иностранного, Москва 1976.

W o ź $\mathrm{n}$ i е w i c z W., Текстовые и внетекстовые лингвокогнитивные лакуны $b$ прочтении художественного текста в инокультурных условиях как иингводидактическая проблема, [в:] Glottodydaktyka i jej konteksty interkulturowe, red. A. Wołodźko-Butkiewicz, W. Zmarzer, Warszawa 2006.

Г у д к о в Д.Б., Теория и практика межкультурной коммуникации, Москва 2003.

Д е м ь я н к о в В.З., Понимание, [в:] Краткий словарь когнитивных терминов, ред. Е.С. Кубрякова и др., Москва 1996.

3 а л е в с к а я А.А., Некоторые проблемы теории понимания текста, „Вопросы языкознания" 2002, № 3, с. 62-74.

3 и м н я я И.А., Психология обучения неродному языку, Москва 1989.

К а р а у л о в Ю.Н., Русский язык и языковая личность, Москва 1987.

К о б о з е в а И.М., Две ипостаси содержания речи: „значение” и „смысл”, [в:] Язык о языке, ред. Н.О. Арутюнова, Москва 2000.

К р а с н ы х В.В., „Свой” среди „чужих": миф или реальность?, Москва 2003.

Краткий словарь когнитивных терминов, ред. Е.С. Кубрякова и др., Москва 1996.

К у л и б и н а Н.В., О когнитивном и коммуникативном аспектах чтения художестВенной митературы, [в:] Материалы IX Конгресса МАПРЯЛ, Братислава-Москва 1999 , с. 274-289.

Л е о н т ь е в А.А., Психология общения, Москва 2007.

Лу р и я А.Р., Язык и сознание, Москва 1979. 
С о р о к и н Ю.А., Взаимодействие рециииента и текста: теория и прагматика, Москва 1978

Т е р - М и н а с о в а С.Г., Язык и межкультурная коммуникация, Москва 2000.

Язык о языке, ред. Н.О. Арутюнова, Москва 2000.

B a y 1 o n Ch., M i g n o t X., Komunikacja, Kraków 2008.

Glottodydaktyka i jej konteksty interkulturowe, red. A. Wołodźko-Butkiewicz, W. Zmarzer, Warszawa 2006.

G o 1 k a M., Bariery w komunikowaniu i społeczeństwo (dez)informacyjne, Warszawa 2008.

K o m o r o w s k a H., Metodyka nauczania języków obcych, Warszawa 2001.

P a l i ń s k i A., Sprawność czytania w nauczaniu języka rosyjskiego, Warszawa 1983. 